\title{
An Exploratory Analysis of Stream Teratogenicity and Human Health Using Zebrafish Whole-Sediment Toxicity Test
}

\author{
Matthew Dellinger ${ }^{1, *}$, Michael J. Carvan ${ }^{2}$, Rebekah H. Klingler ${ }^{2}$, Joseph E. McGraw ${ }^{3}$ and \\ Timothy Ehlinger ${ }^{1}$
}

1 Department of Biological Sciences, University of Wisconsin-Milwaukee, 3209 N. Maryland Avenue Milwaukee, WI 53211, USA; E-Mail: ehlinger@uwm.edu

2 School of Freshwater Sciences, University of Wisconsin-Milwaukee, 600 E. Greenfield Ave. Milwaukee, WI 53204, USA; E-Mails: carvanmj@uwm.edu (M.J.C.); klinglr@uwm.edu (R.H.K.)

3 Concordia University Wisconsin-School of Pharmacy, 12800 North Lake Shore Drive, Mequon, WI 53097, USA; E-Mail: joseph.mcgraw@cuw.edu

* Author to whom correspondence should be addressed; E-Mail: mdellinger@ mcw.edu; Tel./Fax: +1-414-955-4954.

Received: 25 October 2013; in revised form: 18 January 2014 / Accepted: 8 February 2014 / Published: 17 February 2014

\begin{abstract}
This study demonstrates a novel application of effect-based toxicity testing for streams that may provide indications of co-perturbation to ecological and human health. For this study, a sediment contact assay using zebrafish (Danio rerio) embryos was adapted to serve as an indicator of teratogenic stress within river sediments. Sediment samples were collected from Lake Michigan tributary watersheds. Sediment contact assay responses were then compared to prevalence of congenital heart disease (CHD) and vital statistic birth indicators aggregated from civil divisions associated with the watersheds. Significant risk relationships were detected between variation in early life-stage (ELS) endpoints of zebrafish embryos $72 \mathrm{~h}$ post-fertilization and the birth prevalence of human congenital heart disease, low birthweight and infant mortality. Examination of principal components of ELS endpoints suggests that variance related to embryo heart and circulatory malformations is most closely associated with human CHD prevalence. Though toxicity assays are sometimes used prospectively, this form of investigation can only be conducted retrospectively. These results support the hypothesis that bioassays normally used for ecological screening can be useful as indicators of environmental stress to humans and expand our understanding of environmental-human health linkages.
\end{abstract}


Keywords: bioassay; zebrafish; Great Lakes; sediment toxicity; congenital heart disease

\section{Introduction}

Evaluation of environmental health presents the challenging task of identifying useful quantifications (indicators) of environmental health [1-3]. Increasing complexities regarding multiple interacting risk factors (chemicals, socio-economic conditions, built environment) suggest a need for cost-effective investigation of environmental exposures with potential human health consequences [4]. This topic is often studied through investigations of human health risk in association with environmental indicators. For example; pesticide concentration time-series and distance to contaminated sites of water systems [5-7]. Others apply indices of biotic integrity as indicators of human health risk in regions where ecological systems are also disturbed [8,9]. We propose that toxicity assays, such as those used in Effect-Directed Analyses (EDA), may provide useful indicators for similar analyses that evaluate toxicity of human-inhabited communities.

The present study uses a zebrafish whole-sediment toxicity test as a screening tool for toxicity in human-inhabited communities and as a risk indicator relating stream teratogenicity to health. Effectsbased toxicity tests are methods developed for use in EDA. The EDA methodology identifies toxic chemicals via an iterative effects-driven process. It was developed as part of the European Union (EU) Watershed Framework Directive (WFD) for assessing risk to stream ecosystems from multiple toxicants [10]. Instead of inferring specific causal relationships for toxic responses, an effects driven approach quantifies biological responses to environmental samples. This study will focus on the Zebrafish (Danio rerio) whole sediment toxicity test (STT) developed by Hollert et al. [11] which is one of the EDA techniques currently used for WFD assessments [11-13]. STT is a comprehensive method for investigating native sediments and water-phase particulate matter without employing extraction procedures, and can estimate bioavailability of particle-bound lipophilic substances and their toxicity to vertebrate development [11-18]. This paper explores the potential to use STT as a teratogenic risk indicator for human birth outcomes, including Congenital Heart Disease (CHD).

CHD is the most common birth malformation in infants occurring in $0.8 \%-1 \%$ of infants [19], and a leading cause of infant mortality [20,21]. The etiologies of these malformations are largely unknown. Only about $2 \%$ of cases are due to known environmental causes such as viruses, drugs and toxins. The majority (about $73 \%-85 \%$ ) of cases are attributed to multifactorial causes [22], including gene-gene interactions, and multiple gene or gene-environment interactions [20]. Studies also suggest a connection between environmental exposures and CHD, including a three-fold increase in hypoplastic left heart syndrome (HLHS, a severe form of CHD) among the offspring of women exposed to solvents during pregnancy $[23,24]$. Preliminary data from the state of Wisconsin have suggested an increased occurrence of HLHS within certain geographical areas of the state [25]. In Milwaukee County, increased occurrence of CHD is associated with proximity to trichloroethylene emitters [25-27]. Because of the heterogeneity of these defects, including differences in their embryogenesis, unique methods to investigate potential environmental risk relationships are needed [20-22]. 
Public health indicators, collected as part of the registration of infant births/deaths by state vital records agencies, are usually analyzed in relation to socioeconomic status (SES) indicators [28]. All three indicators used in the present study (infant mortality, prematurity and low birth weight) have documented associations with lower SES. But these indicators may also directly or indirectly reflect environmental influences. For example, infant mortality and low birth weight are both higher among infants born with congenital anomalies that may result from exposure to teratogenic agents [20,29]. However, it is also the case that exposures to certain teratogenic agents such as trichloroethylene may be more common in locations close to lower SES neighborhoods, and thus be one of the multiple factors leading to higher infant mortality or low birth weight.

In the present study, STT is used to quantify sediment contamination and teratogenicity of watershed ecosystems. Findings represent the local toxic potential from mixed chemicals and stressors. The following analysis provides evidence to evaluate STT as a toxicity indicator that integrates mixed environmental stressors and is relevant to human health. If STT can be developed as a human health toxicity indicator of environmental samples, then multivariate patterns of fish teratogenicity, aggregated to city-bound watersheds, will describe increased risk of negative birth outcomes within the human population.

\section{Experimental Section}

\subsection{Site Selection and Sampling}

Sediments were sampled to represent watershed teratogenicity of Wisconsin civil divisions and Milwaukee ZIP codes (loosely referred to as cities). Sample sites were selected by examining city, township, ZIP code and minor civil division (MCD) boundaries overlaid upon the WIDNR level 5, 10-digit Hydrologic Unit Hierarchy (HUC-10) boundaries using ArcGis 10 (@2001 ESRI). Sediments were sampled from watersheds within the boundaries of 22 cities and four Milwaukee watersheds (the Milwaukee watersheds were joined to ZIP codes) to create a total of 26 ( $n=26$ for risk analysis) human-populated sample areas, generally referred to as cities for brevity (Figure 1). Cities were non-randomly selected based on availability/confidence of CHD health data (in consultation with the Wisconsin Pediatric Cardiac registry) and proximity to Lake Michigan. One upstream site and one downstream site (within municipal boundaries covered by available infant health data) within HUC-10 watersheds were selected to represent stream toxicity for most of the cities. If more than one watershed intersected the city boundaries, then extra sites were sampled to represent the contributing watersheds (zebrafish responses to sediment were later averaged to represent "cities").

We made no assumptions regarding the direction or magnitude of teratogenic differences between upstream and downstream sites. It was assumed, however, that whenever possible an upstream sampling and downstream sampling were necessary to generalize the inputs and accumulation throughout the watershed as it related to city boundaries.

Each site consisted of three near-surface $(0-5 \mathrm{~cm})$ sediment samples per transect using an Ekman dredge. Two transects (totaling 6 dredge "grabs") were sampled 10 meters apart to represent a site. Samples were stored in $100 \mathrm{~mL}$ Nalgene ${ }^{\circledR}$ polypropylene jars and transported on ice. Samples were centrifuged at $680 \times \mathrm{g}$ for $15 \mathrm{~min}$ to separate pore water from sediment and fine particulates. 
Sediments were homogenized and stored at $-20{ }^{\circ} \mathrm{C}$ in Ziploc ${ }^{\circledR}$ plastic freezer bags for toxicity testing and chemical analysis.

Figure 1. Sampling design illustrating regional elements: watershed, civil division (referred to as cities), stream/river, and sediment sampling sites ( 1 = Upstream, 2 = Downstream).

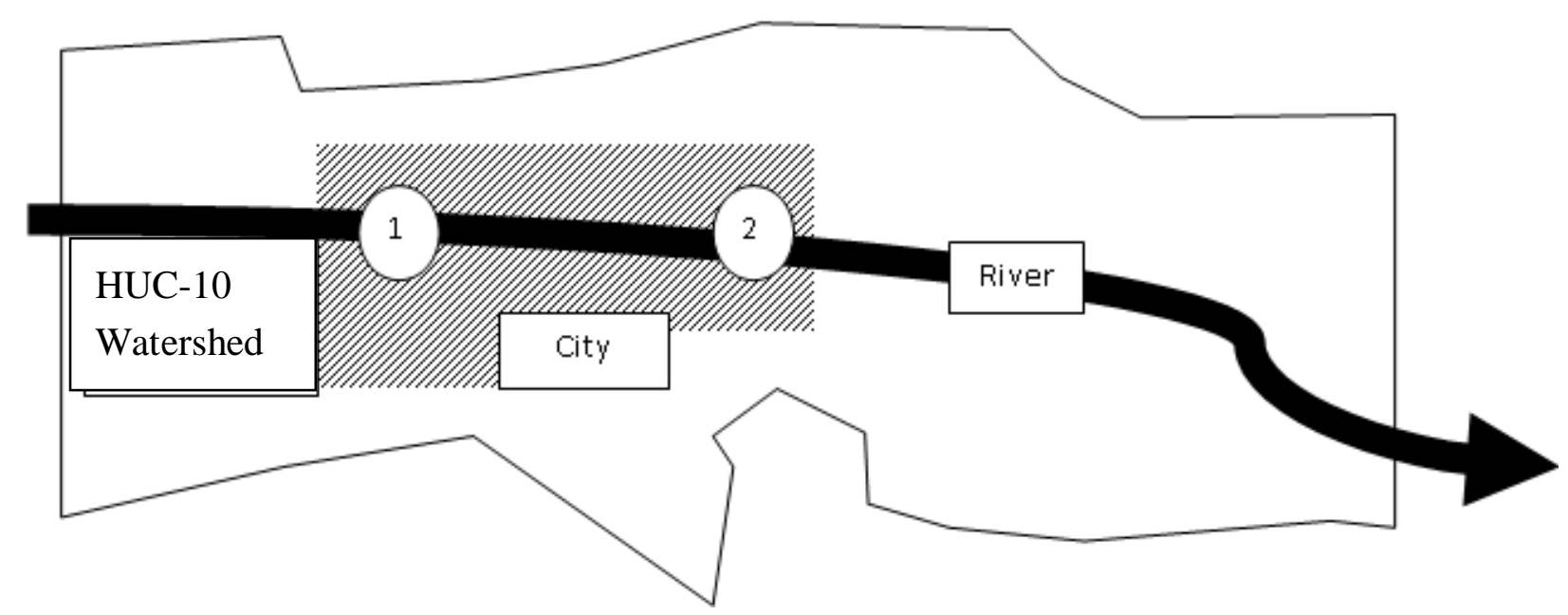

\subsection{Health Data Collection}

Data on occurrence of congenital heart defects were obtained from The Wisconsin Pediatric Cardiac Registry (WPCR). Operation of the WPCR was reviewed and approved by the lead institution (Children's Hospital of Wisconsin) and the other participating clinics and hospitals. Starting 1 January 2000 the WPCR registered families of infants with CHD whose mothers were resident in Wisconsin at the infant's birth [29]. Participating physicians from seven clinical centers throughout the state refer patients to the WPCR. Diagnostic exclusions include infants with an isolated patent foramen ovale (PFO) or patent ductus arteriosus (PDA), electrical conduction disturbances of the heart without an associated structural abnormality and acquired heart diseases, such as Kawasaki's, rheumatic fever or endocarditis. Diagnoses of registered patients are confirmed by clinical examination and either echocardiography, catheterization, surgery or autopsy. For purposes of this study, all CHD diagnoses were aggregated. Data collected through medical records or the WPCR questionnaire on minor civil division of birth residence were used to assign cases to the appropriate geographic unit. From 2000 through 2009, more than 5,000 CHD cases have been registered.

Data on infant mortality (death of a live born infant occurring in the first 12 months of life), prematurity (births of infants between 30 and 37 weeks of gestation), and low birth weight (infants born weighing less than 2,500 g) were obtained through a data sharing agreement with the Wisconsin Bureau of Health Information. Minor civil division recorded on the birth registration form was used in the analysis. As indicated above, data were aggregated by civil political boundaries due to the reliance on DHS birth data to scale birth outcome occurrence. Spatial analysis used ArcGis 10 (C2001 ESRI), to map watersheds onto political boundaries for comparison with human health data.

\subsection{Sediment Chemical Analysis}


Twenty-five of the sites were selected for chemical analysis based on proximity to the Lake Michigan coast. Three high profile persistent bioaccumulative toxics expected to occur in both sediment and human tissues were analyzed in the sediments. A total of 27 sediment samples from 11 different cities (including all the Milwaukee samples) were analyzed for the following chemical contaminants: Polychlorinated biphenyls (PCBs), total dioxins, and polybrominated diphenyl ethers (PBDEs). Chemical analysis was developed and performed using pesticide grade solvents. Sediment samples were lyophilized and sifted (1 mm screen) then subjected to organochlorine extraction in hexane using an ASE 150 accelerated solvent extractor [30]. Dioxin/PCB and PBDE fractions were collected via multilayer column chromatography [31].

PBDE samples were analyzed via UHPLC MS/MS using a Dionex RSLC 3000 UHPLC and an AB Sciex 4000 QTrap [32]. Limit of quantification was $0.42 \mathrm{ng} \cdot \mathrm{g}^{-1}$ sediment for each of the measured PBDE congeners $(47,99,100,153,154$ 183, and 209). Total PBDEs were calculated from the aforementioned congeners. Dioxin/PCB samples were analyzed using a Thermo Ultra Trace GC with PTV inlet, AS3000 autosampler, and ECD detector. Initial oven temperature was $180{ }^{\circ} \mathrm{C}$ for $1 \mathrm{~min}$ then $2.5^{\circ} \mathrm{C}$ per min to $270{ }^{\circ} \mathrm{C}$ for $30 \mathrm{~min}$ (total run time $65 \mathrm{~min}$ ). Ten mcl samples were injected onto Dioxin DB column $60 \times 0.25 \mathrm{~mm}, 0.25$ micron film thickness. Standards curves were created with $\mathrm{r}^{2}$ values $>0.98$ for individual coplanar PCB and dioxin standards. Injections of known standard mixtures of PCDFs and non-coplanar PCBs were performed with the method to ensure no co-elution with measured standards within the method. Limit of quantitation for each of the PCB congeners (77, 81, 105, 114, 118, 123, 126, 156, 157, 167, 169, and 189) and dioxin congeners (1,2,3,4,7,8,9-HpCDD and OCDD) were $0.029 \mathrm{ng} \cdot \mathrm{g}^{-1}$ sediment. Total PCBs and Dioxins were calculated via summation of the aforementioned congeners.

It was necessary to assess oxygen demand to evaluate the effects of toxicity from factors associated with, but not necessarily causally linked to, chemical contaminants. To investigate the role of anoxic sediment conditions on embryo toxicity, total oxygen demand (TOD) was assessed on 40 of the sediment samples. TOD was recorded over five days (2 $\mathrm{g}$ of sample in $300 \mathrm{~mL}$ water) using an YSI 5000 oxygen probe (YSI Inc. Yellow Springs, Ohio, OH, USA) [33].

\subsection{Zebrafish Sediment Contact Assay}

Sediment samples were prepared $2 \mathrm{~h}$ before testing. Twenty four-well microtiter plates were filled with $0.5 \mathrm{~g}( \pm 0.01 \mathrm{~g})$ of native defrosted sediment and covered with Embryo 2, "E2" water [34]. Sediment and water were warmed to $27^{\circ} \mathrm{C}$ prior to embryo exposure.

Zebrafish embryos were collected from breeding populations (Ekkwill strain) at the Children's Environmental Sciences Health Core Center (CEHSCC). At $2 \mathrm{~h}$ post fertilization (HPF), embryos were added to the prepared microtiter plates at a density of one embryo per well and exposed to the native sediment for $46 \mathrm{~h}$ at $27{ }^{\circ} \mathrm{C}$ (un-agitated). At 48HPF embryos were transferred to clean mictrotiter plates with fresh E2 water and observed for 15 Early Life-stage (ELS) endpoints using a dissecting microscope. Embryos were returned to the incubator $\left(27^{\circ} \mathrm{C}\right)$ for an additional $24 \mathrm{~h}$ and observed again at 72HPF for ELS endpoints. The following ELS endpoints were recorded at 48HPF and 72HPF: General Characteristics, (Dead, Un-hatched, Underdeveloped, and Hypopigmentation) Edemas, (Cardiac, Yolk, Abdominal, and Cranial) and Structural Malformations (Body Axis, Somite 
Development, Tail, Eyes, Heart, Circulation, and Head). All sediment samples were tested at least three times ( $\mathrm{n} \geq 18$ embryos, with three plate-independent replicates of six eggs) per experiment (13 experiments were run in total). Each plate contained a negative control row (Aerated, buffered water without sediment) of embryos $(n=6$, per plate). Figure 2 describes the design.

Figure 2. Conceptual Diagram of Experimental Design.

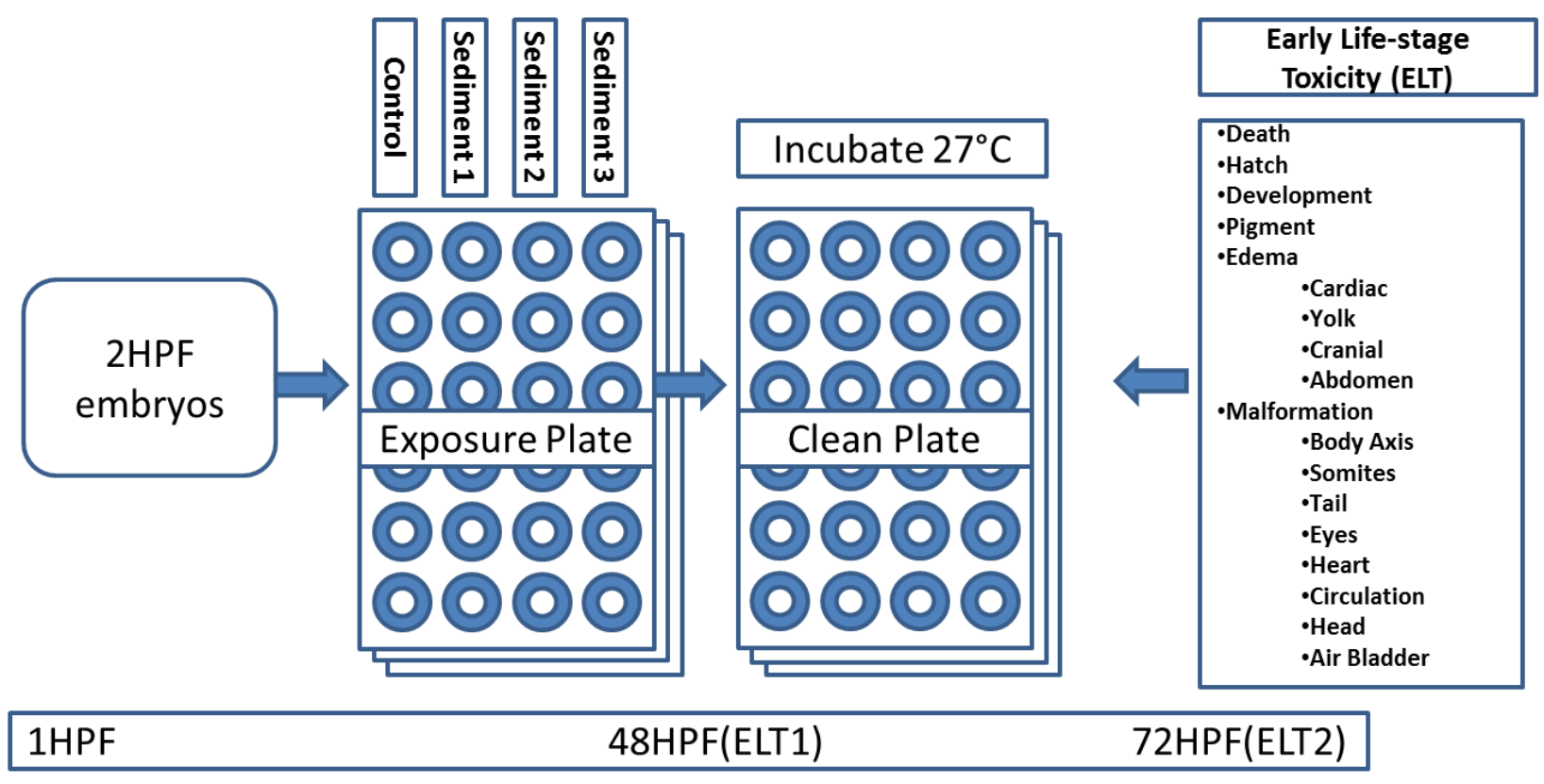

\subsection{Treatment of Data and Analysis}

The STT results were compared to prevalence of human birth outcomes in the corresponding cities. Because STT is a measure of teratogenicity, birth prevalence of CHD and vital statistic indicators of infant health were selected as response variables potentially representing human teratogenic effects in the units sampled. Finally, the relationship between STT, sediment characteristics, and persistent bioaccumulative toxic (PBT) chemicals that may be relevant to local human health was investigated.

Statistical analyses were conducted using JMP 9.0 ((C2010 SAS institute). Sediment contaminant data were examined for divergence from normal distributions and were $\log 10$ transformed to adhere to the distributional assumptions of statistical tests. Test values for STT were standardized relative to controls by subtracting the mean responses for organisms exposed to clean sediment for replicates run on each day.

This study makes no a priori assumptions regarding the particular significance of each early life stage response that was recorded. To characterize these biological responses in way that could be analyzed as teratogenic stress, a conservative approach using non-rotated principal components was applied. Principal components for STT response values were calculated using JMP 9 ((C2010 SAS institute). Four components were derived using pair-wise estimation to describe the variance of ELS endpoints. These components were averaged per city and compared to public health indicators using a non-parametric risk analysis (regression using Weibull probability density function). All eight cities and four zip codes from the chemical analysis (described below) were included in the larger dataset for 
the human health risk analysis. Twenty-six human populations (cities or Milwaukee Zip codes) in total were connected to the stream samples for risk analysis.

In order to investigate the assay's responsiveness to selected contaminants thought to be relevant to human health, principal components were also used as response variables in a multiple regression analysis using sediment contaminants as predictor variables (PCB, PBDE and Dioxin). The multiple regression analysis used the subset of 25 sediment samples from eight cities and four zip codes along the coast of Lake Michigan.

\section{Results}

\subsection{Characterization of Early Life-Stage Endpoints Using Principal Component Analysis}

The distributional properties of all ELS responses to sediment exposure at the 48 and $72 \mathrm{~h}$ observation points are summarized in Table 1 respectively. Principal components were calculated for these responses and bi-plots showing the relationships are presented in Figures 3 and 4 . These components describe response patterns of malformations, mortality and developmental rate; the loading scores for these are displayed in Table 2.

Table 1. Treatment summary statistics of early life-stage endpoints: death, hatch, development, lack of pigmentation, cardiac edema, yolk edema, cranial edema, abdominal edema, malformation of body axis, somite development, tail malformation, eye malformation, heart/heartbeat malformation, circulatory malformation, and head malformation. Replicates consisted of six embryos yielding a maximum possible response of six. (a) $48 \mathrm{~h}$ post-fertilization, (b) $72 \mathrm{~h}$ post-fertilization

\begin{tabular}{cccc}
\hline \multicolumn{4}{c}{ a. Early Life-stage Endpoints_-48 h } \\
\hline 48HPF ELSE & Mean & Std Dev & Max \\
Dead & 2.311 & 1.91 & 6 \\
Unhatched & 3.69 & 1.91 & 6 \\
Underdeveloped & 2.69 & 1.83 & 6 \\
HypoPigment & 0.51 & 1.09 & 5 \\
Ed:Cardiac & 0.04 & 0.22 & 2 \\
Ed:Yolk & 1.03 & 1.45 & 6 \\
Ed:Cranial & 0 & 0 & 0 \\
Ed:Abdom & 0.05 & 0.27 & 3 \\
Mal:Axis & 0.07 & 0.29 & 2 \\
Mal:Somite & 1.83 & 1.63 & 5 \\
Mal:Tail & 0.12 & 0.41 & 4 \\
Mal:Eyes & 0.06 & 0.25 & 2 \\
Mal:Heart & 0.23 & 0.66 & 4 \\
Mal:Circ & 0.09 & 0.41 & 4 \\
Mal:Head & 0.06 & 0.26 & 2 \\
\hline
\end{tabular}


Table 1. Cont.

\begin{tabular}{cccc}
\hline \multicolumn{4}{c}{ b. Early Life-stage Endpoints-72 h } \\
\hline 72HPF ELSE & Mean & Std Dev & Max \\
Dead & 2.65 & 2.05 & 6 \\
Unhatched & 3.03 & 1.97 & 6 \\
Underdeveloped & 2.01 & 1.77 & 6 \\
HypoPigment & 0.81 & 1.28 & 5 \\
Ed:Cardiac & 0.56 & 0.92 & 5 \\
Ed:Yolk & 0.89 & 1.21 & 5 \\
Ed:Cranial & 0.04 & 0.23 & 2 \\
Ed:Abdom & 0.06 & 0.32 & 3 \\
Mal:Axis & 0.53 & 0.80 & 4 \\
Mal:Somite & 0.41 & 0.84 & 5 \\
Mal:Tail & 0.40 & 0.74 & 3 \\
Mal:Eyes & 0.20 & 0.55 & 3 \\
Mal:Heart & 0.94 & 1.24 & 5 \\
Mal:Circ & 1.14 & 1.29 & 5 \\
Mal:Head & 0.26 & 0.64 & 3 \\
\hline
\end{tabular}

Figure 3. Scatterplots of the scores for pairs of principal components overlaid with a matrix of two-dimensional representations of factor loading of early life-stage endpoints recorded at $48 \mathrm{~h}$ post-fertilization. Labeled biplot rays show eigenvectors of endpoints relative to each component in multivariate space. (A) $\mathrm{X}$-axis represents component 1 and $\mathrm{Y}$-axis represents component 2. (B) X-axis represents component 3 and $\mathrm{Y}$-axis represents component 4.

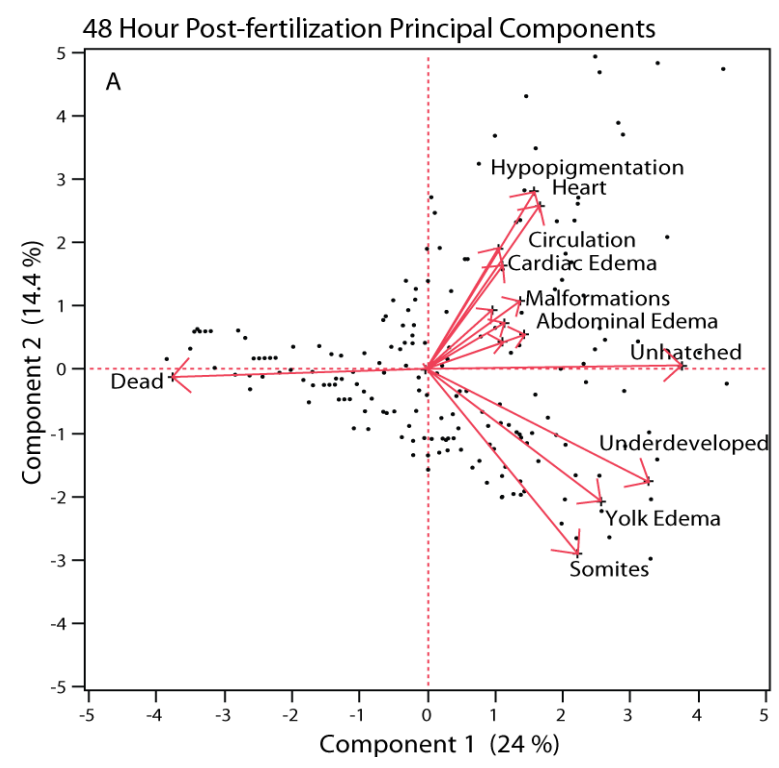

(A)

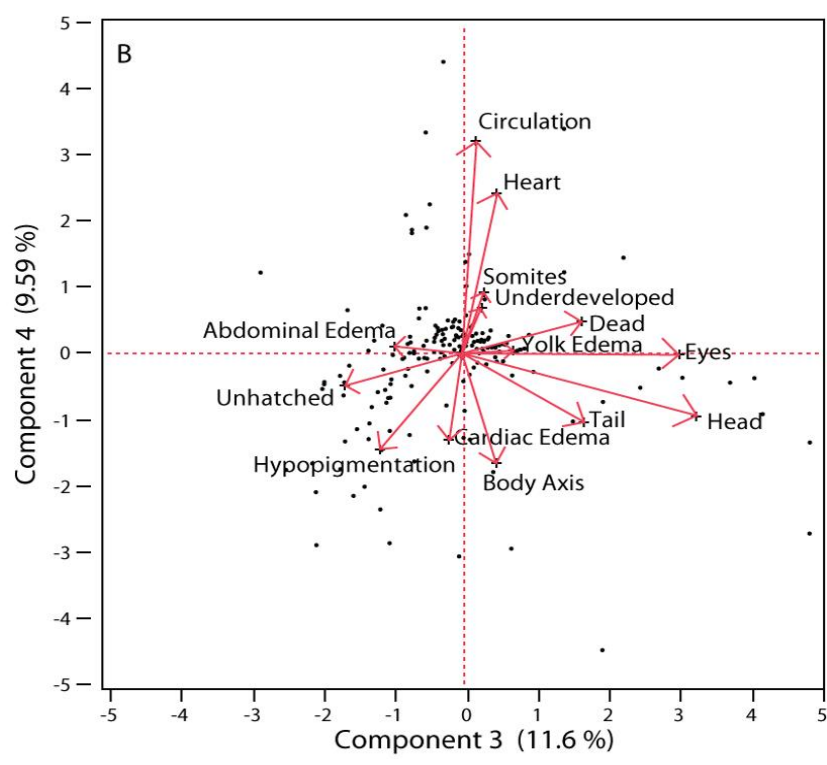

(B) 
Figure 4. Scatterplots of the scores for pairs of principal components overlaid with a matrix of two-dimensional representations of factor loading of early life-stage endpoints recorded at $72 \mathrm{~h}$ post-fertilization. Labeled biplot rays show eigenvectors of endpoints relative to each component in multivariate space. (A) $\mathrm{X}$-axis represents component 1 and $\mathrm{Y}$-axis represents component 2. (B) $\mathrm{X}$-axis represents component 3 and $\mathrm{Y}$-axis represents component 4.

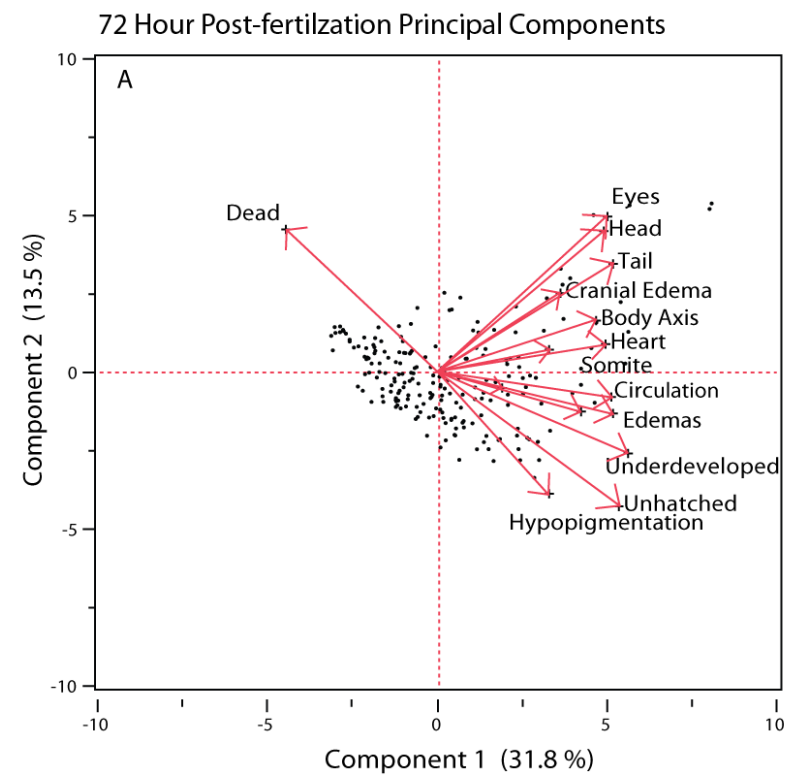

(A)

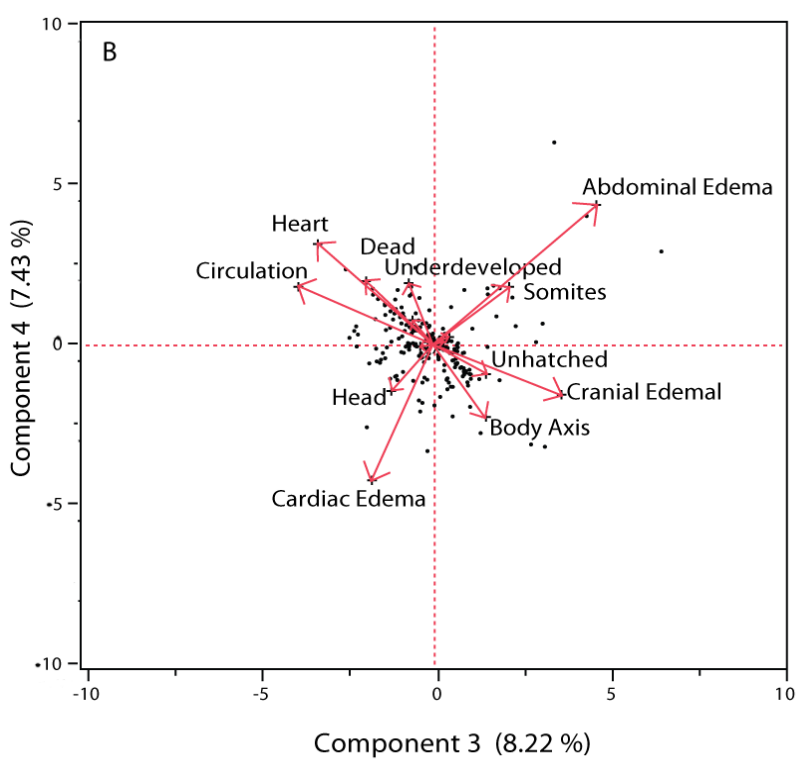

(B)

Table 2. Principal components loading scores of early life-stage endpoints (ELSE). Loading scores with an absolute value greater than 0.4 are displayed in bold. (a) $48 \mathrm{~h}$ postfertilization, (b) $72 \mathrm{~h}$ post-fertilization.

\begin{tabular}{ccccc}
\hline a. Loading Scores for Principal Components- $\mathbf{4 8 ~ h}$ \\
\hline 48HPF ELSE & PC1 & PC2 & PC3 & PC4 \\
Dead & -0.85 & -0.03 & 0.38 & 0.11 \\
Unhatched & 0.85 & 0.01 & -0.37 & -0.11 \\
Underdeveloped & 0.74 & -0.40 & 0.06 & 0.15 \\
Hypopigment & 0.36 & 0.63 & -0.26 & -0.33 \\
Ed:Cardiac & 0.25 & 0.37 & -0.04 & -0.30 \\
Ed:Yolk & 0.58 & -0.47 & 0.16 & 0.01 \\
Ed:Cranial & 0 & 0 & 0 & 0 \\
Ed:Abdom & 0.22 & 0.21 & -0.21 & 0.02 \\
Mal:Axis & 0.26 & 0.16 & 0.11 & -0.37 \\
Mal:Somite & 0.50 & -0.66 & 0.07 & 0.21 \\
Mal:Tail & 0.33 & 0.12 & 0.39 & -0.23 \\
Mal:Eyes & 0.31 & 0.24 & 0.69 & -0.004 \\
Mal:Heart & 0.38 & 0.58 & 0.11 & 0.55 \\
Mal:Circ & 0.24 & 0.43 & 0.05 & 0.72 \\
Mal:Head & 0.26 & 0.09 & 0.74 & -0.21 \\
\hline
\end{tabular}


Table 2. Cont.

\begin{tabular}{ccccc}
\hline b. Loading Scores for Principal Components- & $\mathbf{7 2 ~ h}$ \\
\hline 72HPF ELSE & PC1 & PC2 & PC3 & PC4 \\
Dead & -0.55 & 0.56 & -0.24 & 0.25 \\
Unhatched & 0.66 & -0.53 & 0.19 & -0.11 \\
Underdeve & 0.69 & -0.32 & -0.08 & 0.24 \\
Hypopigment & 0.40 & -0.49 & -0.04 & -0.01 \\
Ed:Cardiac & 0.52 & -0.16 & -0.22 & -0.53 \\
Ed:Yolk & 0.64 & -0.17 & -0.07 & 0.09 \\
Ed:Cranial & 0.45 & 0.31 & 0.46 & -0.20 \\
Ed:Abdom & 0.24 & -0.06 & 0.58 & 0.54 \\
Mal:Axis & 0.58 & 0.20 & 0.19 & -0.28 \\
Mal:Somite & 0.41 & 0.09 & 0.27 & 0.22 \\
Mal:Tail & 0.64 & 0.43 & 0.06 & 0.03 \\
Mal:Eyes & 0.62 & 0.61 & 0.04 & 0.01 \\
Mal:Heart & 0.61 & 0.12 & -0.41 & 0.39 \\
Mal:Circ & 0.64 & -0.10 & -0.48 & 0.23 \\
Mal:Head & 0.61 & 0.56 & -0.14 & -0.18 \\
\hline
\end{tabular}

At both time points, the first principal component (PC1) captured variance between mortality and occurrence of malformations (inverse correlations between death and occurrence of malformations is expected). Both Figure 3 (48 h) and Figure 4 (72 h) indicate that the variation between mortality and malformations produced a strong patterning effect within the data. At 48HPF, the second principal component (PC2) was strongly associated with higher levels of hypopigmentation, circulatory malformation, and heart malformations. This 48HPF PC2 was inversely associated with developmental rate and yolk edemas (Table $2(48 \mathrm{~h})$ ). Similar patterns were found at the 72HPF third principal component (PC3) in which higher PC3 scores were associated with more cranial and abdominal edema, and inversely associated with heart and circulatory malformation (Table 2 (72 h)).

\subsection{ELS Responses and Infant Health}

Zebrafish ELS responses were tested for risk-relationships with infant health data from the corresponding communities using a non-parametric risk regression in JMP 9.0 (SAS 2010). Aggregated infant mortality rate for these Lake Michigan communities was about 8.4 per 1,000 births (range 2.8 to 14.2). This is notably higher than the overall state infant mortality rates for this same time period (6.5 from 2000 to 2009). Aggregated percent low birth weight for the communities was about $6.9 \%$ (range 3.8 to 9.7) which matches the overall state percentage of $6.9 \%$ from 2000-2009. Rates for aggregated CHD averaged about 9.7 per 1,000 births (range 0 to 20.6).

The 48HPF components did reveal one significant association with infant health (Chi-Squared: 4.534, Prob > Chi-Squared: 0.032). PC2 at 48 HPF (slower zebrafish development) was significantly associated with infant mortality (relative risk 0.739, lower CI: 0.578, upper CI: 0.973). The 72HPF components showed significant risk-relationships with three infant health outcomes. PC1 at 72HPF (slower zebrafish development and more malformations) was significantly associated with prevalence of infant mortality (Figure 5A) and PC3 at 72HPF (more heart and circulatory malformations) was 
associated with prevalence of congenital heart disease (Figure 5B). The significant association illustrated by Figure 5A describes a relative risk of 0.742 (lower CI: 0.633, upper CI: 0.879). The significant association in Figure 5B describes a relative risk of 1.214 (lower CI: 1.025, Upper CI: 1.443). There was also a significant relationship between low birth-weight and the 72 HPF PC4 (Chi-Squared: 4.2, Prob > Chi-Squared: 0.043). Relative risk of low birth-weight and 72 HPF PC4 is 0.779 (lower CI: 0.633, Upper CI: 0.991)

Figure 5. Risk-regression of STT ELS principal components and prevalence of birth outcomes. Prevalences are calculated as incidence of death within first year of life, or diagnosis of congenital heart disease, divided by total births for that time period in the corresponding city or ZIP code. Lines represent the 10th, 50th, and 90th percentiles of the fitted relationship. (A) Congenital heart disease and 72HPF principal component 3, Chi-Squared: 9.714, Prob > Chi-Squared: 0.002. (B) Infant mortality and 72HPF principal component 1, Chi-Squared: 4.845, Prob > Chi-Squared: 0.028.

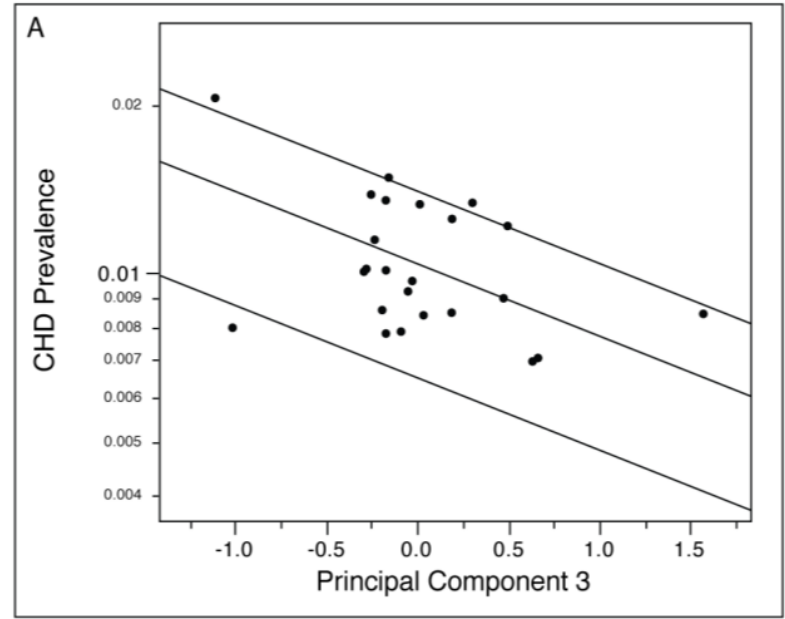

(A)

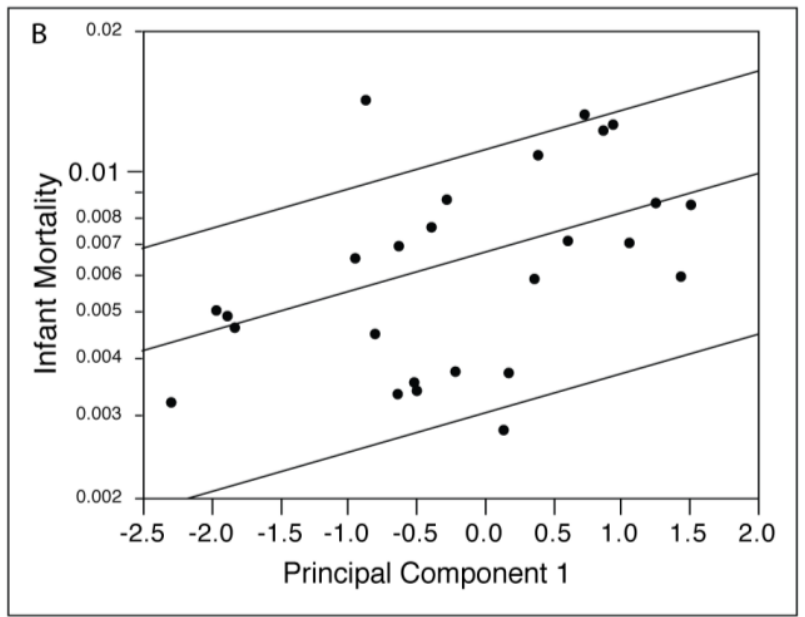

(B)

\subsection{Chemical Contamination of Sediments in Lake Michigan Coastal Streams}

Contamination levels of three lipophilic persistent bioaccumulative toxic chemicals for the 25 sample sites $(n=25)$ are shown in Figure 6 . These are only a subset of the samples used in the risk tests. Downtown/downstream Racine (ROOT_RAC1) was the most contaminated site at 1,098.71 ng $\sum$ PCB $\mathrm{g}^{-1}$ sediment, $4.23 \mathrm{ng} \sum$ Dioxin $\mathrm{g}^{-1}$ sediment, and 21.56ng $\sum \mathrm{PBDE} \mathrm{g}^{-1}$ sediment. The least contaminated site was midstream Kewaunee (KEWR_KEWAN2) with: $<$ MDL $\sum$ PCB g ${ }^{-1}$ sediment, $<$ MDL $\sum$ Dioxin $\mathrm{g}^{-1}$ sediment, and $0.43 \mathrm{ng} \sum \mathrm{PBDE} \mathrm{g}{ }^{-1}$ sediment. Compared to the amount of PCB and dioxin observed in the sediments, PBDE contamination was relatively low. These results clearly demonstrate varying levels of chemical contamination (type and magnitude), with some sites/cities yielding highly contaminated sediment.

Total oxygen demand (TOD) was assessed in a separate subset of the sediment samples. During the oxygen demand tests, none of the sediments tested dropped below the critical limit of $2.0 \mathrm{mg} \mathrm{L}^{-1}[12,16,17]$ within $72 \mathrm{~h}$ (embryos for the current study were only exposed to sediment for $48 \mathrm{~h}$ ). None of the sediments that were tested for oxygen demand and also exhibiting $100 \%$ mortality 
approached the lethal dissolved oxygen concentration of $0.88 \mathrm{mg} \mathrm{L}^{-1}$ during the five-day TOD experiment. After five days, two of the TOD-tested samples dropped to $1.7 \mathrm{mg} \mathrm{L}^{-1}$, and $1.85 \mathrm{mg} \mathrm{L}^{-1}$ dissolved oxygen. These values are associated with growth retardation but not necessarily malformation or mortality $[12,17]$. Nevertheless, those two samples did yield high levels of mortality and developmental retardation in the embryos.

Figure 6. Chemical contaminates ng/g sediment from eight cities and four Milwaukee rivers, totaling 25 samples in 12 civil divisions (some upstream, some downstream). The $\mathrm{x}$ axis lists sample codes which name the Milwaukee-bound river or city, 1's represent furthest downstream (relative to city boundaries) 3's represent furthest upstream (relative to city boundaries) 2's represent sites that were either from equally contributing, but separate, watersheds or midstream sites. A. $\sum$ PCB, B. $\sum$ Dioxin, and C. $\sum$ PBDE

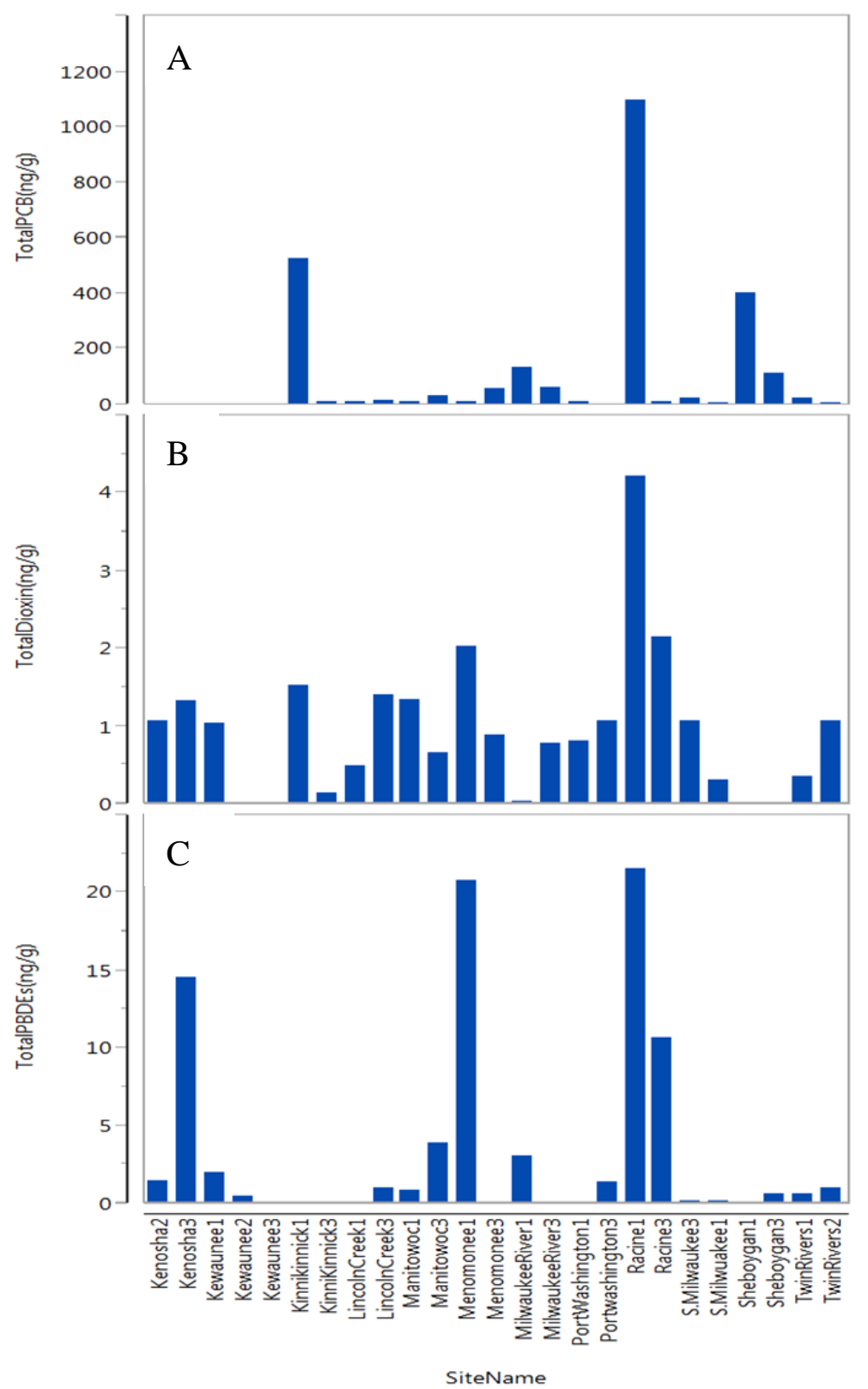




\subsection{Early Life-Stage Response to Sediment Characteristics}

Overall, the regression models did not reveal strong associations between chemicals of concern and zebrafish embryo responses. PCBs were significantly associated with principal component scores for five of the eight regression analyses (Tables 3 and 4). The highest $r^{2}$ value for these models was 0.18 for the model connecting embryo death with logPCB contamination (Table 3 (PC1 Model)). TOD (analyzed on a subset of the samples) was significantly correlated with all Principal Components (of the subset) at 48HPF ( $\mathrm{r}^{2}$ range: $\left.0.087-0.208\right)$ and PCs 2,3 and 4 at 72HPF ( $\mathrm{r}^{2}$ range: $\left.0.136-0.181\right)$.

Table 3. Standard least squares multiple linear regression effects for $48 \mathrm{~h}$ post-fertilization principle components. Model parameters are ng/g sediment of: Total PBDEs congeners, total PCB congeners, and total Dioxins. All sediment contaminant values were log transformed. T-Ratio is the ratio of the estimate to its standard error.

\begin{tabular}{|c|c|c|c|c|c|}
\hline \multicolumn{3}{|c|}{ a. PC1 Model $\left(R^{2}=0.18, P=0.0001\right)$} & \multicolumn{3}{|c|}{ b. PC2 Model $\left(R^{2}=0.05, P=0.0627\right)$} \\
\hline PC1 (48HPF) & Estimate & t Ratio & PC2 (48HPF) & Estimate & t Ratio \\
\hline$\sum \mathrm{PCB} n g / \mathrm{g} *$ & -0.72 & -4.21 & $\sum \mathrm{PCB}$ ng/g * & -0.41 & -2.69 \\
\hline$\sum$ Dioxin ng/g & -2.84 & -2.68 & $\sum$ Dioxin ng/g & 0.62 & 0.66 \\
\hline$\sum$ PBDE ng/g & -0.1 & -0.23 & $\sum$ PBDE ng/g & -0.12 & -0.31 \\
\hline \multicolumn{3}{|c|}{ c. PC3 Model $\left(R^{2}=0.06, P=0.0449\right)$} & \multicolumn{3}{|c|}{ d. PC4 Model $\left(\mathrm{R}^{2}=0.01, P=0.68\right)$} \\
\hline Prin3 (48HPF) & Estimate & t Ratio & Prin4 (48HPF) & Estimate & t Ratio \\
\hline$\sum \mathrm{PCB} n g / g *$ & 0.39 & 2.85 & $\sum$ PCB ng/g & 0.03 & 0.22 \\
\hline$\sum$ Dioxin ng/g * & -0.53 & -0.62 & $\sum$ Dioxin ng/g & 0.55 & 0.64 \\
\hline$\sum$ PBDE ng/g & 0.17 & 0.51 & $\sum \mathrm{PBDE} n \mathrm{ng} \mathrm{g}$ & 0.14 & 0.39 \\
\hline
\end{tabular}

Note: $* p<0.05$.

Table 4. Standard least squares multiple linear regression effects for $72 \mathrm{~h}$ post-fertilization principle components. Model parameters are ng/g sediment of: total PBDEs congeners, total PCB congeners, and total Dioxins. All sediment contaminant values were log transformed. T-Ratio is the ratio of the estimate to its standard error.

\begin{tabular}{|c|c|c|c|c|c|}
\hline \multicolumn{3}{|c|}{ a. PC1 Model $\left(\mathrm{R}^{2}=0.034, P=0.183\right)$} & \multicolumn{3}{|c|}{ b. PC2 Model $\left(\mathrm{R}^{2}=0.087, P=0.005\right)$} \\
\hline PC1 (72HPF) & Estimate & t Ratio & PC2 (72HPF) & Estimate & t Ratio \\
\hline$\sum$ PCB ng/g & -0.32 & -1.87 & $\sum \mathrm{PCB} n g / \mathrm{g} *$ & 0.48 & 3.43 \\
\hline$\sum$ Dioxin ng/g & -1.14 & -0.82 & $\sum$ Dioxin ng/g & -0.21 & -0.24 \\
\hline$\sum$ PBDE ng/g & -0.35 & -0.62 & $\sum$ PBDE ng/g & 0.42 & 1.22 \\
\hline \multicolumn{3}{|c|}{ c. PC3 Model $\left(\mathrm{R}^{2}=0.033, P=0.191\right)$} & \multicolumn{3}{|c|}{ d. PC4 Model $\left(\mathrm{R}^{2}=0.084, P=0.007\right)$} \\
\hline PC3 (72HPF) & Estimate & t Ratio & PC4 (72HPF) & Estimate & t Ratio \\
\hline$\sum$ PCB ng/g & -0.14 & -1.35 & $\sum \mathrm{PCB} n g / \mathrm{g} *$ & 0.30 & 3.05 \\
\hline$\sum$ Dioxin ng/g & -0.26 & -0.42 & $\sum$ Dioxin $n g / g$ & 0.46 & 0.77 \\
\hline$\sum$ PBDE ng/g & -0.26 & -1.05 & $\sum$ PBDE ng/g & 0.19 & 0.80 \\
\hline
\end{tabular}

Note: $* p<0.05$. 


\section{Discussion}

\subsection{Implications of ELS Endpoint Response to City-Bound Watersheds}

The literature supports STT as a useful tool to sensitively detect toxic effects of sediments and exhibits high ecological relevance (since it accounts for bioavailability of contaminants) [10-17]. Whereas previous studies using fish teratogenicity have focused on targeted watersheds to investigate expected environmental perturbation [10-17], the current study demonstrates that this technique could also serve as a toxic screen for human communities with uncharacterized environmental health.

The availability of the Wisconsin Pediatric Cardiac Registry presented an opportunity to investigate a human health outcome with suspected geographically-linked risk factors [35,36]. CHD occurrence, relative to other human health indicators, may be sensitive to environmental stress. While CHDs are the most common birth defects, they are still relatively rare. This can hinder the confidence that rates calculated for small geographic areas reflect meaningful differences among communities. This issue was considered and the cities with potentially suspicious birth-prevalence were noted in JMP 9.0 (C2010 SAS institute). We observed that the lesser-populated cities did not occupy the extreme values describing the probability distribution displayed in Figure 5(A,B). For this exploratory study, it was not necessary to assume specific causal pathways between distinct diagnoses of CHD and teratogenic stress. Therefore, all diagnoses of CHD were included for analysis and were aggregated across ten years.

There may be geographic misclassification of congenital heart defect occurrence due to maternal mobility during pregnancy. Many studies, however, suggest limited exposure misclassification due to residential mobility [37-42]. Geographic misclassification of the three other infant health indicators is also possible. Addresses are self-reported on the birth record, and subject to various errors (use of mailing address and not residence, misspelling of town or city names etc.). However, this should present limited, if any impact, on the findings.

Studies that aggregate human health data geographically are often criticized since aggregate data cannot characterize within-group variability in exposure and confounder variables or "ecologic fallacy" $[43,44]$. Due to ecologic bias (the difference between ecological and individual associations) some studies may be considered less useful for understanding causal relationships. This is a fair criticism for studies that attempt to describe risks to individuals. However, exploratory studies investigating the ability of toxicity assays to holistically screen for environmental human health risk must consider populations. Individual risk assessment should remain in the realm of analyses that more directly assess exposures. Other works have explored the possibility of connecting ecological measures to human population health $[8,9]$ echoing the desire to develop similar screening methodology.

The significant relationship between infant health outcomes and STT principal components suggests a potential to develop useful environmental health indicators from these patterns. In this study a relationship was observed between the PC1 (which seemed to represent a lingering, generalized stress-response) at $72 \mathrm{HPF}$ and infant mortality (which is often cited as a generalized population health metric). Zebrafish have also been utilized to elucidate underlying mechanisms of cardiac development and human congenital heart diseases, as well as potential pathways that may modulate cardiac regeneration [45-47]. It therefore stands to reason that, despite obvious structural differences between 
fish and mammal hearts, PC3 could indicate a response that is analogous to pathways producing human CHD. We cannot speculate, however, on what the specific molecular mechanisms or exposure pathways may be for the current study.

The relationships observed between vital statistics and principal components are unsurprising. Previous work supports the notion that these indicators in Wisconsin are closely related to social determinants of health [28,48-51]. The design of the current study did not accommodate controlling for social determinants of health. Nevertheless, meaningful interpretation is possible. Given the trends observed in previous work with WI vital statistics [48] it is likely that geographic areas with higher health disparities contain features that would increase stream toxicity. Certain ZIP codes in Milwaukee, for example, contain socially-disadvantaged neighborhoods alongside streams which receive considerable urban runoff. The impoverished nature of these areas, both urban and rural, was evident at the time of sediment collection.

\subsection{Linking ELS Endpoint Assays to Sediment Chemical Contamination}

It is important to note that the chemical investigation was meant to characterize sediment toxicity response to PBT chemicals that are of human health concern. Strong relationships between these chemicals and the teratogenicity assay would have supported the notion that the testing regime responds to human-relevant contamination in a screening capacity. Multivariate models revealed weak, but significant, associations between STT responses and PCBs. The TOD experiment also revealed weak but significant associations with STT responses. The TOD results suggest that this was not the main driver of zebrafish toxicity in these samples. The budget and timeframe for this NIEHS pilot project were limited. Therefore, other factors such as metals and polycyclic aromatic hydrocarbons (PAHs) were not assessed. The low $\mathrm{R}^{2}$ values of the models suggest that other factors, perhaps contaminants not measured in this study, could be responsible for the teratogenic responses characterized by the principal component analysis. Sediments contaminated with PAHs and heavy metals are known to induce many of the effects reflected in the principal components [52-54]. PBDEs were investigated due to recent interest as a chemical of emerging concern in the Great Lakes region and their potential similarity to PCBs [3,55]. Teratogenic response in zebrafish has been documented in response to PBDEs [56-58]. However, concentrations of total polybrominated diphenyl ethers from the sediments of these streams were sparse and did not seem to affect the STT results. BDE-209 was the most frequently observed congener of PBDE in these samples, which corroborates for Great Lakes streams what is suggested by previous studies on Great Lakes sediments [59,60].

A high tolerance for anoxic conditions increases the appeal of using zebrafish as model organisms for toxicity testing of native (unaltered) sediments. The fishes' tendency to tolerate stressful conditions allows researchers to observe subtle, non-lethal endpoints such as abnormalities in circulation and cardio-vascular development. The principal components analysis allowed for a generalized characterization of teratogenic response. This eliminated the potential bias of selecting individual endpoints to investigate or the need to categorize observations into "lethal or non-lethal" to create mortality-based metrics. PC3 (which was linked to CHD in our analysis) did not show any significant relationship to the chemicals observed in our models. If a similar, larger-scale analysis revealed the 
same trends, it would suggest that other chemicals should be investigated to assess a link between environmental contaminants and CHD.

Strecker et al. [17] observed that a $72 \mathrm{~h}$ pre-test incubation of sediments in the plate wells can be used to establish minimal levels of oxygen even above the sediment surface. In zebrafish embryo contact tests with native sediments from Lake Skadar (Montenegro), oxygen concentrations rapidly decreased upon addition of the sediments to levels as low as $0.8 \mathrm{mg} / \mathrm{L}$, but recovered to 2.5 and $3.5 \mathrm{mg} / \mathrm{L}$ after 72 and $144 \mathrm{~h}$ respectively [17]. These observations suggested that, during the initial mixing procedure, dissolved oxygen is rapidly used up by inorganic and organic redox processes; upon stabilization of the sediment surface, however, low but sufficient oxygen conditions are re-established with time. In sediments from the current study, TOD was significantly correlated with ELS responses (more so at $48 \mathrm{HPF}$ than $72 \mathrm{HPF}$ ). It is possible that other factors leading to increased oxygen demand also lead to teratogenic response. Furthermore, oxygen demand in sediments can alter the bioavailability of toxic substances such as mercury compounds [61] and other metals [62]. The protocol used in the present study does not allow us to make the distinction between oxygen stress and response to pollution. However, the results seem to suggest a stronger influence of hypoxia during the $48 \mathrm{~h}$ exposure period. The $72 \mathrm{HPF}$ observations, after $24 \mathrm{~h}$ of development in clean water, were more informative when compared to watershed contamination conditions and public health metrics.

\section{Conclusions}

This work demonstrates the use of bioassays to characterize toxic (teratogenic) response to stream sediments in a manner compatible with probabilistic risk modeling. Toxicity patterns across city-bound watersheds were successfully generalized for risk analysis. Significant relationships were observed between the mean toxicity responses and the human health indicators associated with these cities. The hypothesis that significant risk-relationships would exist between public health patterns and effect-directed assessment is thus supported.

Interpretation of the principal components and the risk analysis indicate an increased risk of historic infant mortality in cities with streams yielding higher levels of ELS malformations and slower development at both observation times. This included developmental delays, edemas, and structural malformations. PC2 at 48HPF and PC1 at 72HPF may describe a generalized stress-response that could represent stressed streams in communities of low socio-economic status. Furthermore, principal components describing variance in heart malformations and some edemas at 72HPF were significantly associated with increased incidences of congenital heart disease in humans.

The relationship between CHD and sediment toxicity could be due to high-leverage data points (Figure 5A). This is especially problematic since CHD is relatively rare. Despite these limitations, there remains an incentive to investigate CHD in an ecologic context with zebrafish. Though structurally distinct from human hearts, zebrafish cardiogenesis is often proposed as a useful model for understanding human cardiovascular development [45-47]. TCDD dosing, for example, has been linked to heart malformation in zebrafish embryos [63].

Though the observed associations were significant, further investigation is required to elucidate the potentially relevant co-exposures between humans and streams beyond speculation. Potential exposure linkages abound: For example, the most toxic sites occurred in rivers adjacent to urban or industrial 
runoff (e.g., Milwaukee and Racine sites). The residents of these locations presumably work and live in close proximity to the same runoff sources. Co-exposures could include contaminants such as lead which is of particular health concern to urban residents and gardeners. This is especially so when older homes are demolished or renovated in the dense urban residential sectors of Milwaukee. Similar considerations would be true of PAHs, which are known to affect sediment toxicity scores and are also suspected human health hazards to urban residents [64-66]. TOD in sediments could indicate high chemical oxygen demand from urban runoff due to high impervious surface and lack of riparian buffer. Personal communication with southern Milwaukee neighborhood organizations has revealed that lack of green space in these neighborhoods is a serious limitation to healthy activity. Exercise and fresh air may serve as meaningful environmental health indicators and should not be discounted when considering maternal and childhood health outcomes.

Screening tools should not be held to the expectation of representing an exposure assessment. Nor do we suggest effects-based toxicity assays can replace exposure assessment. Nevertheless, similar responses between the sentinel or screening populations and human populations bolster the idea that environmental screening tools yield toxicologically meaningful information for humans. Further investigation will be required to determine if STT is capable of quantifying environmental perturbation relevant to the health of human populations or co-exposures.

Ecological risk assessors face increasing demands to assess more chemicals, with greater speed and accuracy, and to do so using fewer resources and experimental animals. Furthermore, new approaches in biological and computational sciences should be applied to meet these challenges [67]. Reduction of cost and time for testing, broader coverage of chemicals and their mixtures, reduction of animal suffering, and increased integration of toxicologic and population-based data remain priority areas for advancing risk assessment [68]. It is important to note that, at the current level of development, STT is non-specific by design and does not inform researchers as to the presence of specific contaminates or stressors in the environment. Toxicology, epidemiology, and risk assessment research face an insurmountable volume of potential toxic agents mixed together within dynamic biological, political, and geographical systems $[3,48]$. This application of STT allows for analysis and interpretation of toxicological patterns, which could provide the necessary indicators to facilitate monitoring of environmental health.

EDA bioassays normally used for ecological screening may be useful as indicators of environmental stress to humans, and have the potential to expand understanding of linked environmental risks to ecological and human health. Much work remains before sediment contact assays and other EDA techniques can be used to guide risk management or assessment. However, the patterns of teratogenic responses demonstrated here suggest that using information regarding the type and degree of toxicity could be assessed absent of chemical screening. Further calibration (i.e., identifying key embryo malformations for metric calculation) of this technique could allow for the prioritization of chemical screening, which would also increase the efficiency of biomonitoring efforts.

\section{Acknowledgments}

This study was funded by the National Institute of Environmental Health-sponsored Children's Environmental Health Sciences Core Center through the University of Wisconsin-Milwaukee. 
The Village of Mount Pleasant and the UW-Milwaukee Dept. of Biological Sciences provided additional support. Funding also provided by the UWM Center for 21st Century Studies Transdisciplinary Challenge Program. We thank the Wisconsin Department of Health Statistics and the Wisconsin Pediatric Cardiac Registry for sharing data that was central to the work. The authors are grateful to: Christine Cronk, Andrew Pelech, Ray Hoffman, Reinhold Hutz, and Jesse Jensen M.S., for their intellectual contributions to the ideas developed in this work. Christine Cronk provided significant editorial help in the final version of the manuscript. Joseph McGraw conducted the sediment chemical analysis. The field and lab portions of the study would not have been possible without the extensive help of Jesse Jensen, Jared Bozich, Stephen McGuire, Subhomita Ghosh-Roy, James Lokken, Steven Scholzen, and Cameron Patterson.

\section{Author Contributions}

Matthew Dellinger: performed this work as part of his dissertation at the University of Wisconsin-Milwaukee which he completed in 2012. As a PhD candidate he designed the concept and wrote the pilot grant application which received funding from NIEHS. With the assistance of student workers, he performed the field work, processed the laboratory samples, adapted and conducted the zebrafish toxicity assay. Matthew Dellinger is the primary author of this publication. Michael J. Carvan: served as a mentor and committee member to Matthew Dellinger during the dissertation phase of this work. $\mathrm{He}$ is also the co-PI on the NIEHS grant. He provided expertise on zebrafish toxicity and supplied the necessary resources from his lab. He helped adapt the toxicity testing protocol. Michael J. Carvan also provided editorial assistance on the publication. Rebekah H. Klingler: provided editorial assistance and aided in the design of the study. She also performed the primary husbandry duties for zebrafish embryo production. Joseph McGraw: conducted the sediment contaminant analysis in his laboratory, and provided methodological support. Timothy Ehlinger: was the primary academic advisor to the related dissertation work. The field work and toxicity assay were conducted in his laboratory. He was co-PI on the pilot grant. His mentorship was central to the design of this study, particularly the statistical analysis. He provided substantial editorial oversight to the publication.

\section{Conflicts of Interest}

The authors declare no conflict of interest.

\section{References}

1. Sexton, K.; Hattis, D. Assessing cumulative health risks from exposure to environmental mixtures-Three fundamental questions. Environ. Health Persp. 2006, 115, 825-832.

2. Sexton, K. Cumulative risk assessment: An overview of methodological approaches for evaluating combined health effects from exposure to multiple environmental stressors. Int J. Environ. Res. Public Health 2012, 9, 370-390.

3. Dellinger, M.; Ehlinger, T.; Carvan, M. Human Health Effects Review on Chemicals of Emerging Concern; International Joint Comission: Ottowa, ON, Canada, 2011. 
4. Strauss, W.J.; Ryan, L.; Morara, M.; Iroz-Elardo, N.; Davis, M.; Cupp, M.; Nishioka, M.G.; Quackenboss, J.; Galke, W.; Ozkaynak, H.; et al. Improving cost-effectiveness of epidemiological studies via designed missingness strategies. Stat. Med. 2010, 29, 1377-1387.

5. Ochoa-Acuna, H.; Frankenberger, J.; Hahn, L.; Carbajo, C. Drinking-water herbicide exposure in indiana and prevalence of small-for-gestational-age and preterm delivery. Environ. Health Persp. 2009, 117, 1619-1624.

6. Winchester, P.D.; Huskins, J.; Ying, J. Agrichemicals in surface water and birth defects in the united states. Acta Paediatr. 2009, 98, 664-669.

7. Waller, S.A.; Paul, K.; Peterson, S.E.; Hitti, J.E. Agricultural-related chemical exposures, season of conception, and risk of gastroschisis in washington state. Am. J. Obstet. Gynecol. 2010, 202, e1-e6.

8. Hitt, N.P.; Hendryx, M. Ecological integrity of streams related to human cancer mortality rates. Ecohealth 2010, 7, 91-104.

9. Paul, J.F.; McDonald, M.E.; Hedtke, S.F. Stream condition and infant mortality in U.S. Mid-Atlantic states. Hum. Ecol. Risk Asses. 2008, 14, 728-741.

10. Brack, W.; Klamer, H.J.C.; de Ada, M.L.; Barcelo, D. Effect-directed analysis of key toxicants in european river basins-A review. Environ. Sci Pollut. Res. Int. 2007, 14, 30-38.

11. Hollert, H.; Keiter, S.; Koenig, N.; Rudolf, M.; Ulrich, M.; Braunbeck, T. A new sediment contact assay to assess particle-bound pollutants using zebrafish (Danio rerio) embryos. J. Soils Sediment. 2003, 3, 197-207.

12. Fish Embryo Toxicity Assays. Available online: http://www.oecd.org/chemicalsafety/testing/ 36817242.pdf (accessed on 25 October 2013).

13. Keiter, S.; Boettcher, M.; Grund, S.; Seitz, N.; Braunbeck, T.; Hollert, H. Decrease in fish populations in the upper danube river. Environ. Sci Pollut Res. Int. 2009, 21, 186-196.

14. Keiter, S.; Peddinghaus, S.; Feiler, U.; von der Goltz, B.; Hafner, C.; Ho, N.Y.; Rastegar, S.; Otte, J.C.; Ottermanns, R.; Reifferscheid, G.; et al. Dantox-A novel joint research project using zebrafish (Danio rerio) to identify specific toxicity and molecular modes of action of sediment-bound pollutants. J. Soils Sediment. 2010, 10, 714-717.

15. Kosmehl, T.; Hallare, A.V.; Reifferscheid, G.; Manz, W.; Braunbeck, T.; Hollert, H. A novel contact assay for testing genotoxicity of chemicals and whole sediments in zebrafish embryos. Environ. Toxicol. Chem. 2006, 25, 2097-2106.

16. Rocha, P.S.; Bernecker, C.; Strecker, R.; Mariani, C.F.; Pompeo, M.L.; Storch, V.; Hollert, H.; Braunbeck, T. Sediment-contact fish embryo toxicity assay with danio rerio to assess particle-bound pollutants in the tiete river basin (Sao Paulo, Brazil). Ecotoxicol. Environ. Saf. 2011, 74, 1951-1959.

17. Strecker, R.; Seiler, T.B.; Hollert, H.; Braunbeck, T. Oxygen requirements of zebrafish (Danio rerio) embryos in embryo toxicity tests with environmental samples. Comp. Biochem. Physiol. C Toxicol. Pharmacol. 2011, 153, 318-327.

18. Lammer, E.; Carr, G.J.; Wendler, K.; Rawlings, J.M.; Belanger, S.E.; Braunbeck, T. Is the fish embryo toxicity test (fet) with the zebrafish (Danio rerio) a potential alternative for the fish acute toxicity test? Comp. Biochem. Physiol. C Toxicol. Pharmacol. 2009, 149, 196-209.

19. Hoffman, J.I. Incidence of congenital heart disease: II. Prenatal incidence. Pediatr. Cardiol. 1995, $16,155-165$. 
20. Botto, L.D.; Correa, A. Decreasing the burden of congenital heart anomalies: An epidemiologic evaluation of risk factors and survival. Prog. Pediatr. Cardiol. 2003, 18, 111-121.

21. Srivastava, D. Congenital heart defects, trapping the genetic culprits. Circ. Res. 2000, 86, 917-918.

22. Wigle, D.T.; Arbuckle, T.E.; Turner, M.C.; Berube, A.; Yang, Q.; Liu, S.; Krewski, D. Epidemiologic evidence of relationships between reproductive and child health outcomes and environmental chemical contaminants. J. Toxicol. Environ. Health B Crit. Rev. 2008, 11, 373-517.

23. Kuehl, K.S.; Loffredo, C.A. A cluster of hypoplastic left heart malformation in baltimore, Maryland. Pediatr. Cardiol. 2006, 27, 25-31.

24. Loffredo, C. Epidemiology of cardiovascular malformations: Prevalence and risk factors. Am. J. Med. Genet. 2000, 97, 319-545.

25. Cronk, C.E.; Pelech, A.N.; Malloy, M.E.; McCarver, D.G. Excess birth prevalence of hypoplastic left heart syndrome in eastern wisconsin for birth cohorts 1997-1999. Birth Defects Res. 2004, 70, 114-120.

26. Yauck, J.; Malloy, M.E.; Blair, K.; Simpson, P.; Mccarver, D. Closer Residential Proximity to Trichloroethylene-Emitting Sites Increases Risk of Offspring Congenital Heart Defects Among Older Women. Presented at 42nd Annual Meeting of the Society of Toxicology, Salt Lake City, Utah, UT, USA, 9-13 March 2003.

27. Hanson-Morris, K.; Pelech., A. The Wisconsin pediatric cardiac registry: A mechanism for exploring etiologies of congenital heart defects. Wis. Med. J. 2006, 105, 45-48.

28. Wisconsin State Health Plan: Healthiest Wisconsin 2020. Available online: http://www.dhs.wisconsin.gov/hw2020/ (accessed on 3 April 2010).

29. Dellinger, J.A.; Antoniewski, S.; Lemoine, N.; Andrew, P. Etiologic or causal factors of congenital heart defects: Gene-environment interaction hypothesis. Heart Matter. 2008, 11, 1-3.

30. Kiguchi, O.; Kobayashi, T.; Saitoh, K.; Ogawa, N. Pressurized liquid extraction of polychlorinated dibenzo-p-dioxins, polychlorinated dibenzofurans and coplanar polychlorinated biphenyls from contaminated soil. J. Chromatogr. A 2006, 10, 176-182.

31. Liu, H.; Zhang, Q.; Cai, Z.; Li, A.; Wang, Y.J. Separation of polybrominated diphenyl ethers, polychlorinated biphenyls, polychlorinated dibenzo-p-dioxins and dibenzo-furans in environmental samples using silica gel and florisil fractionation chromatography. Anal. Chim. Acta 2006, 557, 314-320.

32. Mascolo, G.; Locaputo, V.; Mininni, G. New perspective on the determination of flame retardants in sewage sludge by using ultrahigh pressure liquid chromatography-tandem mass spectrometry with different ion sources. J. Chromatogr. A 2010, 27, 4601-4611.

33. Delzer, G.C.; McKenzie, S.W. Five-day biochemical oxygen demand. In U.S. Geological Survey Techniques of Water-Resources Investigations, 2003, 3rd ed.; USGS Publications Warehouse: Virgina, VA, USA, 2003. Available online: http://pubs.water.usgs.gov/twri9A/ (accessed on 25 October 2013).

34. Nusslein-volhard, C.; Dahm, R. Zebrafish: A Practical Approach; Oxford University Press: Oxford, MA, USA, 2002.

35. Cronk, C.E.; Gangnon, R.; Cossette, S.; McElroy, J.A.; Pelech, A.N. Modeling geographic risk of complex congenital heart defects in eastern wisconsin. Birth Defects Res. 2011, 91, 631-641. 
36. Cedergren, M.; Selbing, A.; Kallen, B. Geographic variations in possible risk factors for severe cardiac malformations. Acta Paediatr. 2002, 91, 222-228.

37. Shaw, G.M.; Malcoe, L.H. Residential-mobility during pregnancy for mothers of infants with or without congenital cardiac anomalies-A reprint. Arch. Environ. Health 1992, 47, 236-238.

38. Krieger, N.; Chen, J.T.; Waterman, P.D.; Soobader, M.J.; Subramanian, S.V.; Carson, R. Geocoding and monitoring of us socioeconomic inequalities in mortality and cancer incidence: Does the choice of area-based measure and geographic level matter? The public health disparities geocoding project. Am. J. Epidemiol. 2002, 156, 471-482.

39. Lupo, P.J.; Symanski, E.; Chan, W.; Mitchell, L.E.; Waller, D.K.; Canfield, M.A.; Langlois, P.H. Differences in exposure assignment between conception and delivery: The impact of maternal mobility. Paediatr. Perinat. Epidemiol. 2010, 24, 200-208.

40. Fell, D.B.; Dodds, L.; King, W.D. Residential mobility during pregnancy. Paediatr. Perinat. Epidemiol. 2004, 18, 408-414.

41. Canfield, M.A.; Ramadhani, T.A.; Langlois, P.H.; Waller, D.K. Residential mobility patterns and exposure misclassification in epidemiologic studies of birth defects. J. Expo. Sci. Environ. Epidemiol. 2006, 16, 538-543.

42. Chen, L.; Bell, E.M.; Caton, A.R.; Druschel, C.M.; Lin, S. Residential mobility during pregnancy and the potential for ambient air pollution exposure misclassification. Environ. Res. 2010, 110, $162-168$.

43. Wakefield, J. Ecologic studies revisited. Annu. Rev. Public Health 2008, 29, 75-90.

44. Wakefield, J.; Haneuse, S.J. Overcoming ecologic bias using the two-phase study design. Am. J. Epidemiol. 2008, 167, 908-916.

45. Tu, S.; Chi, N.C. Zebrafish models in cardiac development and congenital heart birth defects. Differentiation 2012, 84, 4-16.

46. Bakkers, J. Zebrafish as a model to study cardiac development and human cardiac disease. Cardiovasc. Res. 2011, 91, 279-288.

47. Heideman, W.; Antkiewicz, D.S.; Carney, S.A.; Peterson, R.E. Zebrafish and cardiac toxicology. Cardiovasc. Toxicol. 2005, 5, 203-214.

48. Dellinger, M.; Tofan, L.; Ehlinger, T. Predictive analytics and pattern visualization for human health risk assessment. In BENA Istanbul 2012; Balkan Environmental Association: Istanbul, Turkey, 2012; pp. 709-723.

49. Robert, S.A.; Booske, B.C. US opinions on health determinants and social policy as health policy. Am. J. Public Health 2011, 101, 1655-1663.

50. Vila, P.M.; Swain, G.R.; Baumgardner, D.J.; Halsmer, S.E.; Remington, P.L.; Cisler, R.A. Health disparities in milwaukee by socioeconomic status. Wis. Med. J. 2007, 106, 366-372.

51. Webb, B.C.; Simpson, S.L.; Hairston, K.G. From politics to parity: Using a health disparities index to guide legislative efforts for health equity. Am. J. Public Health 2011, 101, 554-560.

52. Wu, L.; Chen, L.; Hou, J.; Zhang, Y.; Zhao, J.; Gao, H. Assessment of sediment quality of yangtze river estuary using zebrafish (Danio rerio) embryos. Environ. Toxicol. 2010, 25, 234-242.

53. Yang, F.; Zhang, Q.; Guo, H.; Zhang, S. Evaluation of cytotoxicity, genotoxicity and teratogenicity of marine sediments from qingdao coastal areas using in vitro fish cell assay, comet assay and zebrafish embryo test. Toxicol. In Vitro 2010, 24, 2003-2011. 
54. Bartzke, M.; Delov, V.; Stahlschmidt-Allner, P.; Allner, B.; Oehlmann, J. Integrating the fish embryo toxicity test as triad element for sediment toxicity assessment based on the water framework directive approach. J. Soil. Sediment. 2010, 10, 389-399.

55. Klecka, G.; Persoon, C.; Currie, R. Chemicals of emerging concern in the great lakes basin: An analysis of environmental exposures. Rev. Environ. Contam. Toxicol. 2010, 207, 1-93.

56. Chen, X.; Huang, C.; Wang, X.; Chen, J.; Bai, C.; Chen, Y.; Chen, X.; Dong, Q.; Yang, D. BDE-47 disrupts axonal growth and motor behavior in developing zebrafish. Aquat. Toxicol. 2012, 120-121, 35-44.

57. He, J.; Yang, D.; Wang, C.; Liu, W.; Liao, J.; Xu, T.; Bai, C.; Chen, J.; Lin, K.; Huang, C.; et al. Chronic zebrafish low dose decabrominated diphenyl ether (BDE-209) exposure affected parental gonad development and locomotion in F1 offspring. Ecotoxicology 2011, 20, 1813-1822.

58. Usenko, C.Y.; Robinson, E.M.; Usenko, S.; Brooks, B.W.; Bruce, E.D., Pbde developmental effects on embryonic zebrafish. Environ. Toxicol Chem 2011, 30, 1865-1872.

59. Zhu, L.Y.; Hites, R.A., Brominated flame retardants in sediment cores from lakes michigan and erie. Environ. Sci. Technol. 2005, 39, 3488-3494.

60. Song, W.; Ford, J.C.; Li, A.; Sturchio, N.C.; Rockne, K.J.; Buckley, D.R.; Mills, W.J., Polybrominated diphenyl ethers in the sediments of the great lakes. 3. Lakes ontario and erie. Environ. Sci. Technol. 2005, 39, 5600-5605.

61. Taylor, D.L.; Linehan, J.C.; Murray, D.W.; Prell, W.L., Indicators of sediment and biotic mercury contamination in a southern new england estuary. Mar. Pollut. Bull. 2012, 64, 807-819.

62. De Jonge, M.; Teuchies, J.; Meire, P.; Blust, R.; Bervoets, L. The impact of increased oxygen conditions on metal-contaminated sediments part ii: Effects on metal accumulation and toxicity in aquatic invertebrates. Water Res. 2012, 46, 3387-3397.

63. Antkiewicz, D.S.; Burns, C.G.; Carney, S.A.; Peterson, R.E.; Heideman, W. Heart malformation is an early response to tcdd in embryonic zebrafish. Toxicol. Sci. 2005, 84, 368-377.

64. Ding, C.; Zhang, T.; Wang, X.; Zhou, F.; Yang, Y.; Yin, Y. Effects of soil type and genotype on lead concentration in rootstalk vegetables and the selection of cultivars for food safety. J. Environ. Manage. 2013, 122, 8-14.

65. Khillare, P.S.; Jyethi, D.S.; Sarkar, S. Health risk assessment of polycyclic aromatic hydrocarbons and heavy metals via dietary intake of vegetables grown in the vicinity of thermal power plants. Food Chem. Toxicol. 2012, 50, 1642-1652.

66. Hernke, M.T.; Podein, R.J. Sustainability, health and precautionary perspectives on lawn pesticides, and alternatives. EcoHealth 2011, 8, 223-232.

67. Ankley, G.T.; Bennett, R.S.; Erickson, R.J.; Hoff, D.J.; Hornung, M.W.; Johnson, R.D.; Mount, D.R.; Nichols, J.W.; Russom, C.L.; Schmieder, P.K.; et al. Adverse outcome pathways: A conceptual framework to support ecotoxicology research and risk assessment. Environ. Toxicol. Chem. 2010, $29,730-741$. 
68. Committee on Toxicity Testing and Assessment of Environmental Agents, National Research Council (NRC). Toxicity Testing in the 21st Century: A Vision and A Strategy; NRC: Washington, DC, USA, 2007.

(C) 2014 by the authors; licensee MDPI, Basel, Switzerland. This article is an open access article distributed under the terms and conditions of the Creative Commons Attribution license (http://creativecommons.org/licenses/by/3.0/). 